\title{
Mycobacterium obuense, a Rapidly Growing Scotochromogenic Mycobacterium Capable of Forming a Black Product from $p$-Aminosalicylate and Salicylate
}

\author{
By M. TSUKAMURA AND S. MIZUNO \\ The National Sanatorium, Chubu Chest Hospital, Obu, Aichi-Prefecture, Japan 474
}

(Accepted for publication 6 July $197 \mathrm{I}$ )

\begin{abstract}
SUMMARY
Five strains of rapidly growing scotochromogenic mycobacteria were shown to have a capacity to degrade $p$-aminosalicylate and salicylate, forming a black product(s). The organisms differ distinctly from known mycobacterial species that have this capacity, Mycobacterium fortuitum, M. abscessus and M. borstelense, and from other mycobacteria. The organisms are considered to belong to a new species of the genus Mycobacterium and are named Mycobacterium obuense sp. nov.
\end{abstract}

\section{INTRODUCTION}

Penso, Cattaneo, Morellini \& Vicari (1955) observed that Mycobacterium piscium, $M$. thamnopheos and $M$. friedmanni darkened media containing $p$-aminosalicylate (PAS) and thought that the PAS was changed, first, to $m$-aminophenol and then to a dark product. When a group of mycobacteria from soil sources grew on Ogawa egg medium containing $0 . \mathrm{I}$ or $0.2 \%(\mathrm{w} / \mathrm{v})$ PAS the medium became black and catechol was considered an intermediate (Tsukamura, 196I). Tarshis (1964), Medina, Meissner \& Bönicke (1964), and Tsukamura (1965a) reported that PAS degradation was characteristic for $M$. fortuitum, which also converted salicylate to a black product (Tsukamura, I965a) via catechol as an intermediate (Tsukamura, $1965 b$ ). More recently, $M$. abscessus (chelonei) and $M$. borstelense have also been found to degrade PAS and salicylate (Tsukamura, Mizuno \& Tsukamura, 1968; Tsukamura, 1970). All these mycobacteria are rapidly growing, non-photochromogenic mycobacteria. Until now, no organism showing this capacity was found among scotochromogenic mycobacteria. In the course of a co-operative study of Japanese national sanatoria, a rapidly growing scotochromogenic mycobacterium was found to have this ability. Similar organisms were subsequently isolated from the soil. These mycobacteria were shown to belong to a new species.

\section{METHODS}

Strains. Five strains of rapidly growing, scotochromogenic mycobacteria capable of degrading PAS and salicylate have so far been isolated: no. 4388 from the sputum of a patient with pulmonary disease, and nos. 5434, 5435, 5436 and 5437 from soil. The method used for the isolation from soil was as described previously (Tsukamura \& Tsukamura, 1967), but without selection through mouse body.

Tests. One hundred and two tests were used. Ninety-four of the 95 tests described previously (Tsukamura, 1967) were used, omitting a test for tolerance to 8-azaguanine. To these 94 the following eight tests were added: arrangement of bacterial cells when observed microscopically after the Ziehl-Neelsen stain (compact grouping state or dispersed state); peroxidase; tolerance to $5 \mu \mathrm{g}$. ethambutol $/ \mathrm{ml}$. in Ogawa egg medium; tolerance to $0 . \mathrm{I} \%$ 
$(\mathrm{w} / \mathrm{v})$ and $0.2 \%$ (w/v) $\mathrm{NaNO}_{2}$ in Sauton agar; tolerance to I \% (w/v) Tween 80 in Sauton agar; $\alpha$-esterase activity; $\beta$-esterase activity.

Composition of Ogawa egg medium was described previously (Tsukamura, 1967). The composition of Sauton agar is: sodium glutamate, 4.0 g.; $\mathrm{KH}_{2} \mathrm{PO}_{4}, 0.5 \mathrm{~g}$.; $\mathrm{MgSO}_{4} \cdot 7 \mathrm{H}_{2} \mathrm{O}$, $0.5 \mathrm{~g}$.; citric acid, $2.0 \mathrm{~g}$.; ferric ammonium citrate, $0.05 \mathrm{~g}$.; glycerol, $30 \mathrm{ml}$; purified agar, $30.0 \mathrm{~g}$.; distilled water, $970 \mathrm{ml}$., with $\mathrm{pH}$ to 7.0 by $10 \%$ (w/v) KOH.

The methods of these tests were described previously (Tsukamura, 1966; Tsukamura \& Tsukamura, 1968), $\alpha$-Esterase and $\beta$-esterase activities were tested by the method of Käppler (1965). The presence of free naphthylamines in excess of $\mathrm{ro} \mu \mathrm{g} . / \mathrm{ml}$. was expressed as positive reaction.

Estimation of the S-value (similarity coefficient) between two strains was made as described previously (Tsukamura, I966). The hypothetical mean organism (HMO) (Tsukamura \& Mizuno, 1968) was used to express a mean characterization of a species.

Virulence for mice, guinea pigs, rabbits and chickens was tested by the method previously described (Tsukamura \& Tsukamura, 1967).

\section{RESULTS AND DISCUSSION}

Biological and biochemical characters of PAS- and salicylate-degrading, scotochromogenic mycobacteria

Gram-positive; acid-fast; rods (approx. $3 \mu \mathrm{m}$. by 0.5 to $0.7 \mu \mathrm{m}$.); no compact grouping; smooth, yellow or orange colonies after 3 days on Ogawa egg medium and on Sauton agar; scotochromogenic; catalase-positive; peroxidase-negative; $\mathrm{NO}_{3}^{-}$not reduced; 3 day arylsulphatase-negative; 2 week arylsulphatase-positive; PAS and salicylate degraded to black products; growth on $0.2 \%(\mathrm{w} / \mathrm{v})$ PAS in Ogawa egg medium; growth at $28^{\circ}$ and $37^{\circ}$ but not at $45^{\circ}$.

Urease, nicotinamidase, pyrazinamidase and allantoinase activities present but acetamidase, benzamidase, isonicotinamidase, salicylamidase, succinamidase and malonamidase absent.

Acid from glucose, mannose, arabinose, mannitol and sorbitol within 2 weeks at $28^{\circ}$; acid usually from inositol ( 3 out of 5); acid not formed from galactose, xylose, rhamnose and trehalose.

Glycerol, glucose, mannose, galactose, arabinose, xylose (4 out of 5), trehalose, mannitol, sorbitol, fructose, sucrose, ethanol, propan-I-ol, I,2-propanediol, 2,3-butanediol, acetate, succinate, malate, pyruvate and fumarate utilized as sole source of carbon within 2 weeks at $37^{\circ}$; inositol utilized by 3 of 5 ; rhamnose, I,3-butanediol, I,4-butanediol, citrate, benzoate and malonate not utilized.

Glutamate, glucosamine, ethanolamine (by 3 of 5) and trimethylene diamine utilized as simultaneous nitrogen and carbon source; serine, acetamide and benzamide not utilized.

Glutamate, serine, urea, succinamide and $\mathrm{NO}_{3}^{-}$utilized as the sole source of nitrogen; methionine, benzamide and $\mathrm{NO}_{2}^{-}$not utilized; acetamide, pyrazinamide, isonicotinamide, nicotinamide variable.

Tolerant to: $0.05 \%$ and $0.1 \%$ (w/v) salicylate; $5 \mu \mathrm{g}$. ethambutol $/ \mathrm{ml}$.; Io $\mu \mathrm{g}$. thiophen-2carboxylic acid hydrazide $/ \mathrm{ml}$; $0.1 \%$ and $0.2 \%$ (w/v) $\mathrm{NaNO}_{2} ; \mathrm{I} \%(\mathrm{w} / \mathrm{v})$ Tween $80,0.1 \%$ and $0.2 \%(\mathrm{w} / \mathrm{v})$ picric acid and $62.5 \mu \mathrm{g}$. but not $125 \mu \mathrm{g}$. $\mathrm{NH}_{2} \mathrm{OH} . \mathrm{HCl} / \mathrm{ml}$. $\alpha$-esterasenegative; $\beta$-esterase-positive.

Two strains, no. 4388 and 5435, were avirulent when tested in mice, guinea pigs, rabbits and chickens. 
The most important characters of these strains are the abilities to degrade PAS and salicylate, abilities considered characteristic for Mycobacterium fortuitum, M. abscessus and $M$. borstelense (Tsukamura, Mizuno \& Tsukamura, 1968; Tsukamura, 1970), although these three organisms are non-photochromogenic whereas the strains in the present study are scotochromogenic. The S-value between these strains ranged from 85 to $97 \%$ (Table I) and the strains are suggested as belonging to a species.

Table I. S-Value table for rapidly growing scotochromogenic mycobacteria degrading $P A S$ and salicylate

\begin{tabular}{|c|c|c|c|c|}
\hline \multirow{2}{*}{$\begin{array}{c}\text { Strain no. } \\
4388\end{array}$} & \multicolumn{4}{|c|}{ S-Value ( $\%)$} \\
\hline & - & - & - & - \\
\hline 5434 & 93 & - & - & - \\
\hline 5435 & 85 & 90 & 一 & - \\
\hline 5436 & 87 & 92 & 93 & 一 \\
\hline 5437 & 88 & 93 & 96 & 97 \\
\hline
\end{tabular}

Table 2. Comparison between a PAS-and salicylate-degrading scotochromogenic Mycobacterium (Mycobacterium obuense) and other mycobacteria

Species

M. tuberculosis

M. bovis

M. kansasii

M. avium

M. intracellulare

$M$. nonchromogenicum

M. gastri

M. scrofulaceum

$M$. gordonae (tap-water scotochromogens)

M. marinum

M. thermoresistibile

$M$. chitae

$M$. borstelense

M. abscessus

M. fortuitum

M. phlei

M. aurum*

$M$. parafortuitum*

M. vaccae*

$M$. rhodesiae*

M. smegmatis

S-Value between the (Intraspecies mean S-value) 'Permissible low HMOs of M. obuense \pm (Standard deviation) $\dagger$ limit' for a species $\$$ and other species

$\begin{array}{ccc}(\%) & (\%) & (\%) \\ 98 \cdot 0 \pm 1 \cdot 20(n=90) & 95 \cdot 6 & 45 \\ 99 \cdot 2 \pm 1 \cdot 02(n=20) & 97 \cdot 2 & 43 \\ 97 \cdot 0 \pm 2 \cdot 09(n=12) & 92 \cdot 8 & 56 \\ 94 \cdot 4 \pm 2 \cdot 1 \mathrm{I}(n=26) & 90 \cdot 2 & 57 \\ 93 \cdot 0 \pm 2 \cdot 3 \mathrm{I}(n=76) & 88 \cdot 4 & 59 \\ 96 \cdot 2 \pm 2 \cdot 7 \mathrm{I}(n=93) & 90 \cdot 8 & 57 \\ 97 \cdot 3 \pm 2 \cdot 95(n=8) & 91 \cdot 3 & 60 \\ 95 \cdot 3 \pm 2 \cdot 12(n=26) & 91 \cdot \mathrm{I} & 64 \\ 97 \cdot 7 \pm 1 \cdot 36(n=49) & 95 \cdot 0 & 6 \mathrm{I} \\ & & 60 \\ 95 \cdot 1 \pm 4 \cdot 56(n=10) & 86 \cdot 0 & 68 \\ 92 \cdot 8 \pm 2 \cdot 86(n=39) & 87 \cdot \mathrm{I} & 66 \\ 97 \cdot 5 \pm 1 \cdot 73(n=4) & 94 \cdot 0 & 59 \\ 93 \cdot 0 \pm 2 \cdot 10(n=6) & 88 \cdot 8 & 76 \\ 95 \cdot 5 \pm 5 \cdot 0 \mathrm{I}(n=24) & 85 \cdot 5 & 75 \\ 90 \cdot 0 \pm 3 \cdot 74(n=77) & 82 \cdot 5 & 83 \\ 94 \cdot 0 \pm 2 \cdot 63(n=21) & 88 \cdot 7 & 8 \mathrm{I} \\ 92 \cdot 0 \pm 5 \cdot 05(n=34) & 81 \cdot 9 & 69 \\ 92 \cdot 5 \pm 2 \cdot 5 \mathrm{I}(n=6) & 87 \cdot 5 & 79 \\ 94 \cdot 7 \pm 2 \cdot 19(n=\mathrm{I}) & 90 \cdot 3 & 72 \\ 96 \cdot 2 \pm 2 \cdot 16(n=16) & 91 \cdot 9 & \end{array}$

* The HMO of these species were prepared using the characters shown in the text. The HMO of the other species were prepared as written previously (Tsukamura \& Mizuno, 1968).

$\dagger$ The intraspecies mean $S$-value is a mean S-value for the membership of a species to the HMO of itself. The numbers in parentheses are the numbers of strains used for preparation of the HMO.

\$ (Intraspecies mean S-value) $-2 \times$ (standard deviation).

Comparison between the PAS- and salicylate-degrading scotochromogenic mycobacteria and other mycobacteria

The S-values between the HMO of the PAS- and salicylate-degrading scotochromogenic mycobacteria and the HMO of the other mycobacteria are much lower than the 'permissible 
Table 3. Comparison between a PAS- and salicylate-degrading scotochromogenic Mycobacterium (Mycobacterium obuense) and $M$. aurum

\begin{tabular}{lll} 
& \multicolumn{2}{c}{ Mean S-value* $(\%)$ to the HMO of } \\
M. obuense & M. aurum \\
M. obuense & $95 \cdot 00 \pm 3 \cdot 94 \dagger(n=5)$ & $80 \cdot 00 \pm 4 \cdot 30(n=5)$ \\
M. aurum & $8 \mathrm{I} \cdot 4 \mathrm{I} \pm 2 \cdot 38(n=34)$ & $92 \cdot 00 \pm 5 \cdot 05(n=34)$
\end{tabular}

* (Mean S-value) \pm (standard deviation). The number in parentheses is the number of test strains.

$\dagger$ Intraspecies mean S-value.

N.B. There is a significant difference between the intraspecies mean $\mathrm{S}$-value and the interspecies mean $\mathrm{S}$-value ( $P$ less than $0 . \mathrm{I} \%$ by the ' $t$ '-test).

low limit' (Tsukamura, 1969) for the known mycobacterial species (Table 2). The only exception is Mycobacterium aurum. This preliminary comparison indicated that the PASand salicylate-degrading organisms were distinct from all known species except $M$. aurum. The S-value between the HMO of these organisms and the HMO of $M$. aurum is $83 \%$, which is slightly higher than the permissible low limit of $8 \mathrm{I} \cdot 9 \%$ for $M$. aurum. However, the value is much lower than the intraspecies mean S-value of $92.0 \%$ for $M$. aurum (Table 2 ). Thus, even though these two taxons may overlap in their characters, they are probably different from each other.

A numerical comparison of these two taxa (Table 3) showed that they are separable from each other with significant difference between the intraspecies and the interspecies mean S-values.

If, as proposed by Runyon (1965), any taxon differentiable from other taxa is regarded as a species, the taxon consisting of PAS- and salicylate-degrading strains should also be regarded as an independent species. Thus the taxon was named as Mycobacterium obuense nov. sp. The origin of the name is a locality $(\mathrm{Obu})$ where four of five strains have been isolated.

Type strain of Mycobacterium obuense is strain no. 4388 and it has been deposited in the National Collection of Type Cultures, London (NCTC 10778) and in the American Type Culture Collection, Rockville, Maryland, U.S.A. (ATCC 27023).

Characters useful for differentiation of Mycobacterium obuense from other mycobacterial species

The following characters are considered to be important for identification of this species.

(I) Degradation of PAS at $0.2 \%(w / v)$ in the Ogawa egg medium and of salicylate at $0.1 \%(\mathrm{w} / \mathrm{v})$ in the Sauton agar with the production of a black product. One loopful of the test organism is used to inoculate the Ogawa egg medium (the Löwenstein-Jensen medium) containing $0.2 \%(\mathrm{w} / \mathrm{v})$ sodium $p$-aminosalicylate (PAS) or the Sauton agar containing $0.1 \%(\mathrm{w} / \mathrm{v})$ sodium salicylate and the tubes are incubated at $37^{\circ}$ for 7 days. Degradation of PAS or salicylate is shown as a black colouring.

(2) Growth within 3 days on Ogawa egg medium (or Löwenstein--Jensen medium) and on the Sauton agar.

(3) Yellow, wet, smooth colonies on the Sauton agar and on egg media.

(4) $\mathrm{NO}_{3}^{-}$not reduced.

(5) Urease, nicotinamidase, pyrazinamidase and allantoinase are positive among the Io amidase tests of Bönicke (I962). 
Table 4. Differentiation of Mycobacterium obuense from $M$. fortuitum, $M$. abscessus and $M$. borstelense

\begin{tabular}{|c|c|c|c|c|}
\hline \multirow[b]{2}{*}{ Character } & \multicolumn{4}{|c|}{ Percentage of strains showing a positive reaction } \\
\hline & M. obuense & M. fortuitum & M. abscessus & M. borstelense \\
\hline Number of strains tested & 5 & 77 & 24 & 34 \\
\hline Colonial pigmentation & 100 & 0 & 0 & 0 \\
\hline Three day arylsulphatase & 0 & 94 & 79 & 100 \\
\hline Growth on $\mathrm{NH}_{2} \mathrm{OH}$ medium $(0.25 \mathrm{mg} . / \mathrm{ml}$.) & 0 & IOO & 100 & IOO \\
\hline Acid from arabinose & 100 & 0 & 0 & 0 \\
\hline Acid from sorbitol & IOO & 4 & o & 0 \\
\hline L-Serine (as N \& C source) & o & 52 & 100 & 97 \\
\hline Trimethylene diamine (as $\mathbf{N} \& \mathrm{C}$ source) & 100 & 98 & 92 & 0 \\
\hline Nitrate reduction & 0 & 95 & 25 & 0 \\
\hline Allantoinase & 100 & 96 & 4 & 0 \\
\hline Ethanol (as C source) & 100 & 9 I & 13 & 0 \\
\hline Propan-I-ol (as C source) & 100 & 98 & 13 & 0 \\
\hline
\end{tabular}

Table 5. Differentiation of Mycobacterium obuense from other rapidly growing scotochromogenic mycobacteria

Percentage of strains showing a positive reaction

$\overbrace{M . M} \quad M . \quad M$. para- $\quad M . \quad M . \quad M . \quad \begin{gathered}M . \\ \text { thermo- }\end{gathered}$

Character obuense rhodesiae fortuitum* aurum vaccae phlei resistibile flavescens

5
0
0
0
80
100
0
100
0
0
100
100
100

$\begin{array}{lll}16 & 6 & 34\end{array}$

Growth at $45^{\circ}$

Growth at $52^{\circ}$

Nitrate reduction

Salicylate degradation

PAS degradation

Acetamidase

Acid from arabinose

Acid from xylose

Acid from rhamnose

Acid from mannitol

Acid from sorbitol

Glucosamine (as N \& C source)

Acetamide (as N \& C source)

Monoethanolamine (as $\mathrm{N} \&$ C source)

Trimethylene diamine (as N \& C source)

Malonate (as $\mathrm{C}$ source)

$\begin{array}{cccc}0 & 0 & 0 & 53 \\ 60 & 0 & 0 & 94 \\ 100 & 100 & 100 & 9 \\ 0 & 0 & 0 & \end{array}$

$\begin{array}{rrrr}I 2 & 21 & 39 & 5 \\ 0 & 100 & 100 & 0 \\ 0 & 86 & 98 & 0 \\ 0 & 100 & 92 & 100 \\ 0 & 0 & 0 & 0 \\ 0 & 0 & 0 & 0 \\ 100 & 33 & 0 & 0 \\ 0 & 33 & 0 & 0 \\ 0 & 33 & 0 & 0 \\ 100 & 0 & 0 & 0 \\ 100 & 71 & 0 & 0 \\ 0 & 95 & 0 & 0 \\ 0 & 5 & 0 & 0 \\ 0 & 100 & 0 & 0 \\ 0 & 0 & 0 & 0 \\ 0 & 95 & 0 & 0 \\ 0 & 95 & 0 & 0\end{array}$

* Some strains grew at $45^{\circ}$ immediately after isolation from soils.

(6) Glutamate, glucosamine and trimethylene diamine utilized as simultaneous nitrogen and carbon source.

(7) Acid formed from glucose, mannose, arabinose, inositol (variable), mannitol and sorbitol.

Until now, the capacity to degrade PAS and salicylate, forming a black product, has been considered characteristic of three non-photochromogenic mycobacteria, Mycobacterium 
fortuitum, M. abscessus and $M$. borstelense (Tsukamura, Mizuno \& Tsukamura, I968; Tsukamura, 1970). Mycobacterium obuense is the fourth organism that has this capacity. Several characters differentiate $M$. obuense from these three mycobacteria (Table 4). Differentiation from other rapidly growing scotochromogenic mycobacteria is given in Table 5 .

\section{REFERENCES}

BöNICKE, R. (1962). L'identification des mycobactéries à l'aide de méthodes biochimiques. Bulletin de l'Union Internationale contre la Tuberculose 32, $13-76$.

KäPPLER, W. (1965). Acetyl-Naphthylamin-Esterasen-Aktivität von Mykobakterien. Beiträge zur Klinik der Tuberkulose 130, I-4.

Medina, B., MeIssner, J. \& BöNICKe, R. (1964). PAS-Metabolismus schnellwachsender Mycobakterien (Versuche mit C-I4 markierter PAS). In Stoffwechsel und Stoffwechselprodukte von Mycobakterien, pp. I44-I49. Edited by E. Freerksen \& R. Bönicke. Stuttgart: Gustav Fischer Verlag.

Penso, G., Cattaneo, C., Morellini, M. \& Vicari, G. (1955). Studi e ricerche sui micobatteri. XIV. Sul metabolismo del PAS in alcune specie di micobatteri insensibili al PAS. Rendiconti dell' Istituto Superiore di Sanità $\mathbf{1 8}, \mathbf{1 7}-24$.

Runyon, E. H. (1965). Pathogenic mycobacteria. Advances in Tuberculosis Research 14, 235-287.

TARSHIS, M. S. (1964). A PAS medium as an aid in differentiating human and bovine tubercle bacilli and Mycobacterium fortuitum from other mycobacteria. Tubercle 45, 267-27I.

Tsukamura, M. (1961). Formation of a red color product from PAS by certain mycobacteria. Japanese Journal of Tuberculosis 9, 70-79.

Tsukamura, M. (1965a). Salicylate degradation test for differentiation of Mycobacterium fortuitum from other mycobacteria. Journal of General Microbiology 4r, 309-315.

Tsukamura, M. (1965b). Conversion of salicylate to catechol by Mycobacterium fortuitum. Journal of General Microbiology 4I, 317-320.

Tsukamura, M. (1966). Adansonian classification of mycobacteria. Journal of General Microbiology 45, 253-273.

TsuKamURA, M. (1967). Identification of mycobacteria. Tubercle 48, 3II-338.

Tsukamura, M. (1969). Numerical taxonomy of the genus Nocardia. Journal of General Microbiology 56, 265-287.

TsuKamURA, M. (1970). Differentiation between Mycobacterium abscessus and Mycobacterium borstelense. American Review of Respiratory Diseases 101, 426-428.

Tsukamura, M. \& Mizuno, S. (1968). 'Hypothetical mean organisms' of mycobacteria. A study of classification of mycobacteria. Japanese Journal of Microbiology 12, 37I-384.

Tsukamura, M., Mizuno, S. \& Tsukamura, S. (I968). Classification of rapidly growing mycobacteria. Japanese Journal of Microbiology 12, $15 \mathrm{I}-\mathrm{I} 66$.

Tsukamura, M. \& Tsukamura, S. (1967). Further observations on Mycobacterium terrae. A method for isolating slowly growing, non-photochromogenic mycobacteria from soil sources. American Review of Respiratory Diseases 96, 299-304.

Tsukamura, M. \& Tsukamura, S. (1968). Differentiation of mycobacteria by susceptibility to nitrite and propylene glycol. American Review of Respiratory Diseases 98, 505-506. 